\title{
Navegant per la taula periòdica
}

\author{
José Ángel Hernández Santadaría \\ Institut Badalona VII, Badalona
}

L'article presenta una selecció de recursos $i$ activitats que permeten treballar amb l'alumnat de batxillerat els continguts corresponents al currículum de química relacionats amb la taula periòdica i les propietats periòdiques dels elements. La majoria d'aquests materials són digitals, estan disponibles a Internet i formen part de l'aula virtual de química creada per l'autor en l'entorn Moodle.

Paraules clau: taula periòdica, química de batxillerat, recursos digitals, entorn virtual d'aprenentatge

\section{Introducció}

L'actual currículum de la matèria de química de batxillerat (1) inclou diversos continguts relacionats amb la taula periòdica i les propietats periòdiques dels elements. El currículum oficial proposa estudiar a primer curs la descripció dels primers intents de classificació periòdica dels elements, l'establiment de la taula periòdica de Mendelejev, el concepte de periodicitat dels elements a partir de les seves propietats i també la relació entre la distribució dels electrons per nivells i subnivells i la posició dels elements representatius en la taula periòdica. Al segon curs de l'etapa es proposa incorporar l'explicació de la periodicitat d'algunes propietats dels àtoms (volum atòmic, energia d'ionització, electronegativitat) en funció de la seva estructura electrònica.

També hi ha la possibilitat d'ajuntar en la mateixa unitat didàctica tots aquests continguts. L'autor d'aquest article així ho ha fet i ha incorporat a la seva programació de química de primer batxillerat una unitat anomenada "La taula periòdica", que s'imparteix durant el tercer trimestre, formada pels següents apartats:

- Evolució històrica de la classificació dels elements

- La taula periòdica actual

- Configuració electrònica i estructura de la taula periòdica

- Propietats periòdiques
Actualment a Internet es poden trobar nombrosos i diversos materials relacionats amb la taula periòdica. Al llarg dels darrers cursos l'autor hi ha realitzat una cerca i selecció de recursos i activitats. Tots aquests materials, que es van revisant $i$ actualitzant de manera freqüent, s'han organitzat i es posen a disposició de l'alumnat mitjançant un curs de Moodle, l'aula virtual de química (2).

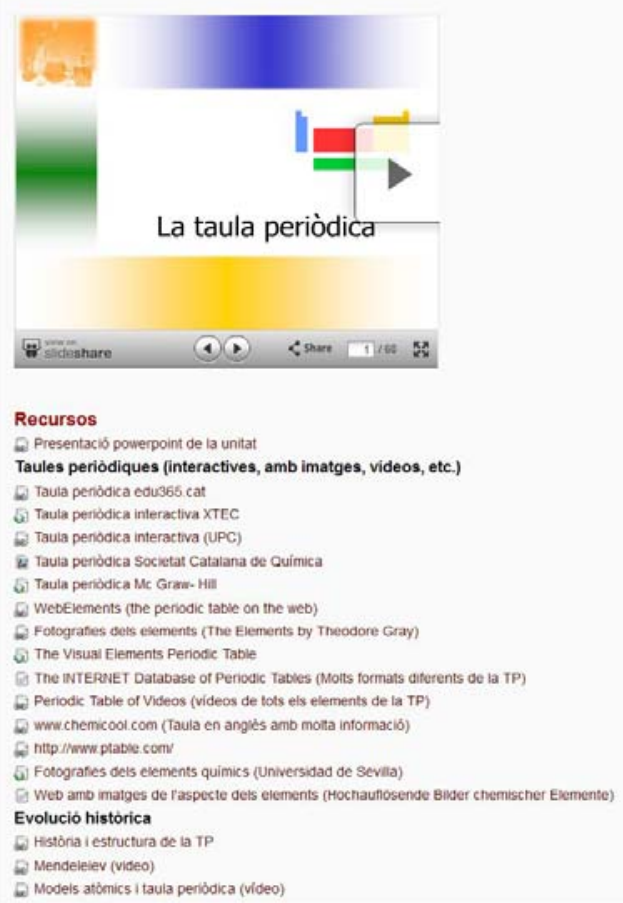

Figura 1. Una mostra dels recursos sobre la taula periòdica que incorpora l'aula virtual de química. 


\section{Descripció dels recursos}

\section{Taules periòdiques}

A Internet hi ha un gran nombre de taules periòdiques disponibles, bona part de les quals permeten accedir a informació detallada sobre el descobriment, història, abundància, estructura, propietats físiques i químiques, obtenció i aplicacions de tots els elements químics. Tres de les taules seleccionades són interactives i presenten tota aquesta informació en català: són les taules de l'edu365.cat (3), I'XTEC (4) i l'Escola Politècnica Superior d'Enginyeria de Manresa - UPC (5).

També es posen a disposició de l'alumnat taules periòdiques interactives en altres llengües, com el castellà i l'anglès. Algunes de les taules més completes i interessats són WebElements (6), chemicool.com (7), ptable.com (8) i la de l'editorial McGraw - Hill (9).

Un dels recursos més interessants incorporats a la nostra selecció són les taules que inclouen fotografies dels elements químics. Possiblement la més atractiva és la que podem trobar al web periodictable.com (10), taula elaborada a partir de les imatges recopilades per Theodore Gray, autor del llibre The Elements recentment publicat en català per la Secció de Ciències i Tecnologia de l'IEC, la Universitat Autònoma de Barcelona i Publicacions de la Universitat de València amb motiu de l'Any Internacional de la Química.

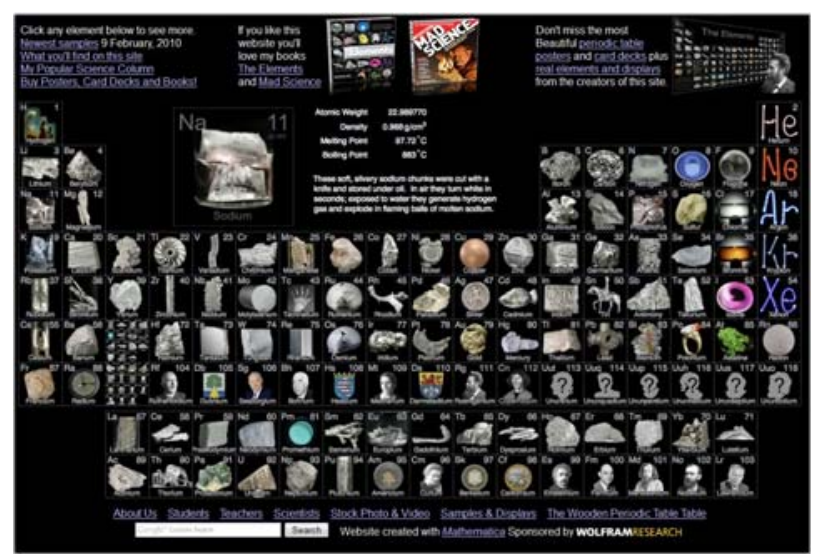

Figura 2. El web periodictable.com.

També podem trobar fotografies de qualitat dels elements químics en altres portals web com jumk.de (11) i educaplus.org (12).

Un recurs ben atractiu és el web The Periodic Table of Videos (13), creat per la Universitat de Nottingham. Aquest espai recull vídeos sobre els 118 elements químics, en els quals s'expliquen les seves característiques més destacades, s'hi poden veure mostres dels elements i diversos experiments. Recentment han incorporat una nova secció anomenada The Molecular Videos en la qual es poden trobar vídeos sobre diversos compostos químics d'interès.

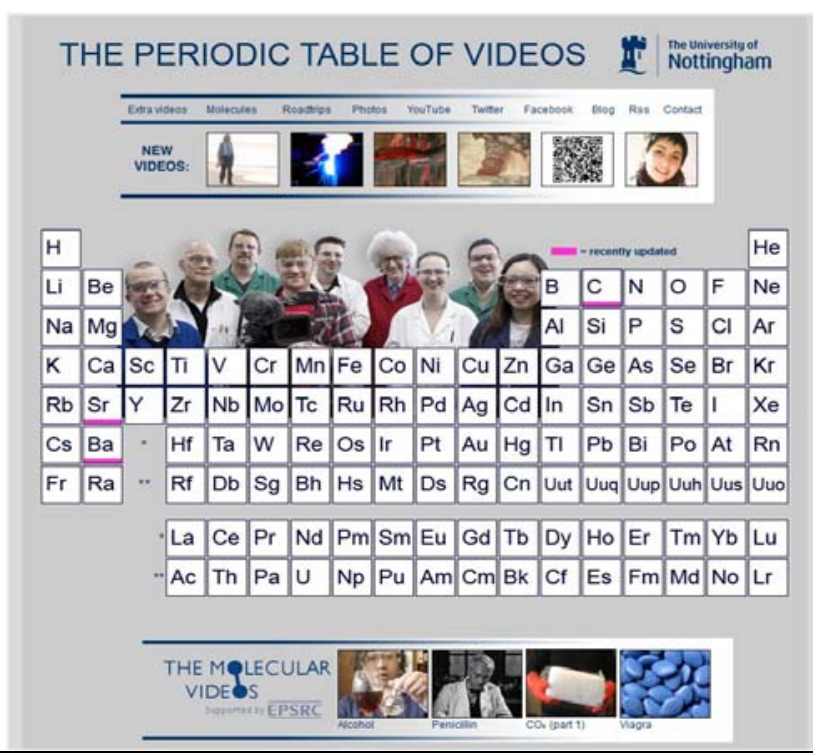

Figura 3. El web The Periodic Table of Videos de la Universitat de Nottingham

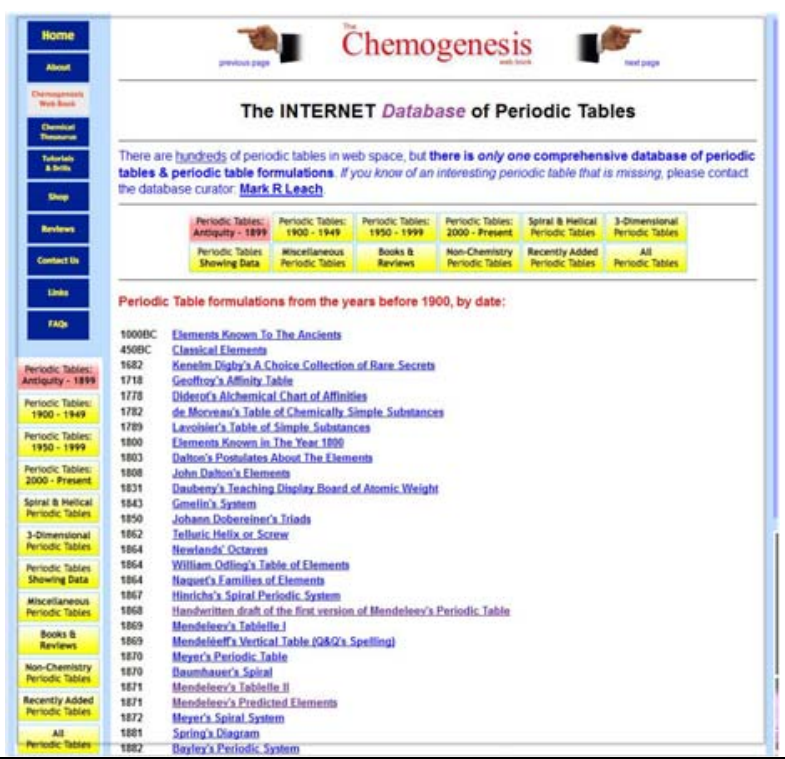

Figura 4. El web The Internet Database of Periodic Tables permet accedir a centenars de formats de la taula periòdica.

A l'aula virtual també s'ha incorporat un arxiu amb la imatge escanejada de la taula periòdica editada per la Societat Catalana de Química. Això permet projectar-la i comentar-la a classe amb l'ajuda de la pissarra digital. Els alumnes poden adquirir a- 
questa mateixa taula periòdica en paper mida DIN A4 i utilitzar-la com a consulta quan realitzen exercicis.

Per últim volem destacar el web The Internet Database of Periodic Tables (14). Es tracta d'una exhaustiva recopilació formada per centenars de taules periòdiques, classificades segons diferents criteris: cronològic (des de l'antiguitat fins els nostres dies), estructural (taules 3D, espirals, helicoïdals, etc.), novetats i taules periòdiques "no químiques" (creacions artístiques, humorístiques, publicitàries, etc.).

\section{Altres recursos sobre la taula periòdica}

L'aula virtual de química posa a l'abast de l'alumnat un bon nombre de recursos digitals sobre la taula periòdica, classificats en diverses categories: taules periòdiques, evolució històrica, taula periòdica actual, origen dels elements químics, propietats periòdiques i recursos complementaris.

Els recursos que formen aquesta selecció es presenten en diversos formats. Predominen els vídeos, però l'alumnat també pot accedir a la informació continguda en pàgines web especialitzades, notícies aparegudes en la premsa electrònica i animacions flash.

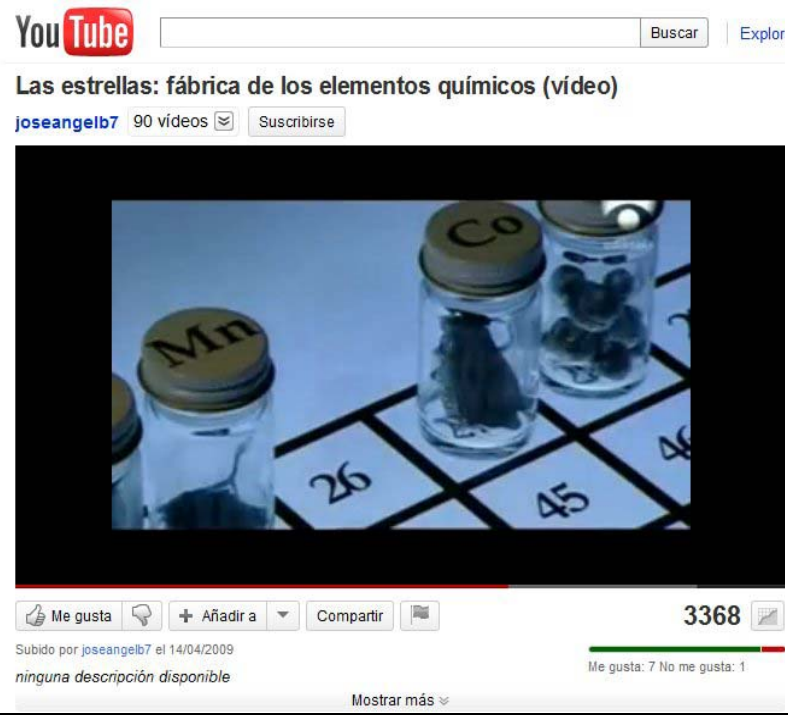

Figura 5. Un dels vídeos sobre la taula periòdica que es pot trobar a l'aula virtual de química

Com a suport a les explicacions del professor a classe, l'autor ha elaborat una presentació, disponible al portal web slideshare.net (15). Aquesta presentació també pot utilitzar-se com a fil conductor de la unitat i conté un resum dels tots els continguts treballats en aquest tema.

\section{Descripció de les activitats}

Les activitats seleccionades permeten que els estudiants treballin els diversos continguts de la unitat. $\mathrm{Hi}$ ha exercicis interactius per practicar els aspectes més bàsics, com el repàs dels noms i símbols dels elements (16) o la seva classificació en grups i períodes (17). Amb aquest mateix objectiu també s'han seleccionat activitats en format JClic (18) i de quadern virtual (19).

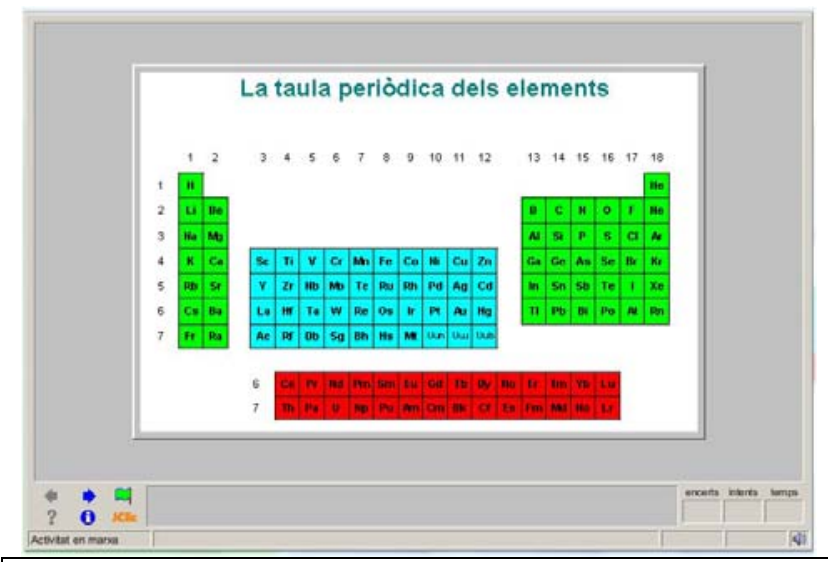

Figura 6. Activitat JClic sobre la taula periòdica

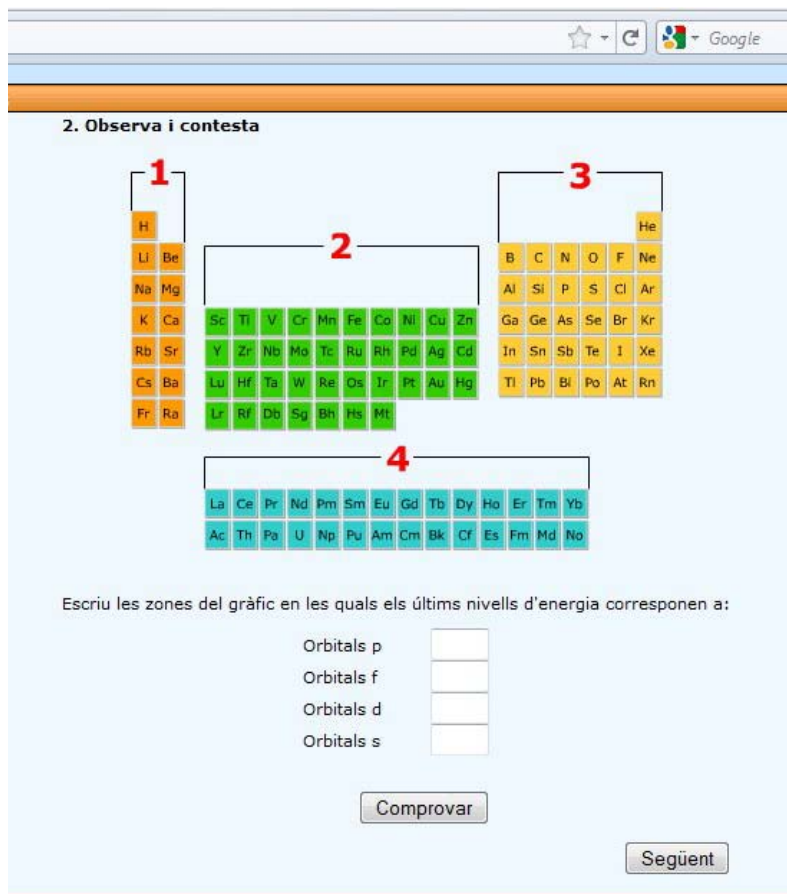

Figura 7. Test inclòs en la taula periòdica del web edu365.cat.

Algunes de les taules periòdiques interactives presentades anteriorment (3, 4 i 5) inclouen dife- 
rents activitats com, per exemple, qüestionaris d'opcions múltiples, exercicis d'autoavaluació, entreteniments i jocs interactius.

També es dediquen algunes sessions de classe a la realització i correcció d'exercicis de "llapis i paper". El professor ha elaborat una col-lecció d'exercicis que l'alumnat es pot descarregar des de l'aula virtual de química en format pdf. La col-lecció conté exercicis de diversos tipus: qüestions obertes de tipus conceptual, qüestions que requereixen la interpretació i anàlisi de taules i gràfics, així com problemes numèrics. Bona part dels exercicis que es proposen són preguntes incloses en les proves de química de les PAU dels últims anys.

Aquesta selecció d'activitats permet tant repassar els conceptes bàsics com aprofundir en els diferents continguts de la unitat. També fa possible que l'alumnat pugui treballar de manera autònoma, adaptant el nombre i tipus d'activitats realitzades al seu ritme de treball.

\section{Construcció d'una taula periòdica gegant}

Per celebrar l'Any Internacional de la Química, el seminari de física i química de l'Institut Badalona VII va proposar als alumnes construir una taula periòdica gegant. Es tractava d'elaborar unes fitxes de mida A4 per a cada element químic, amb la següent informació: nom, nombre atòmic, símbol i una fotografia de l'element (sempre que fos possible). Cada fitxa es completava amb una referència a les aplicacions i usos més habituals de l'element i un parell de fotografies il-lustratives d'aquestes aplicacions.

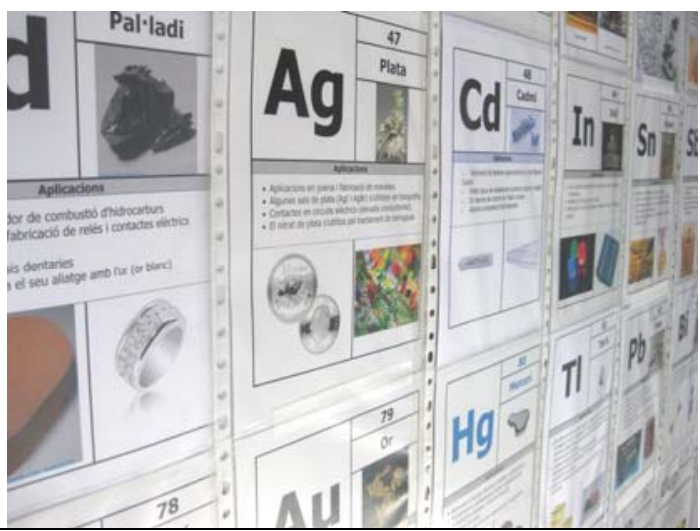

Figura 8. Detall d'algunes de les fitxes que formen la taula periòdica gegant
A l'aula virtual de química els estudiants van trobar totes les indicacions per poder realitzar l'activitat, així com la plantilla de fitxa d'element que havien de descarregar i completar. Els alumnes de $3 r$ d'ESO i els que cursaven la matèria de química a primer de batxillerat van participar en l'elaboració de les fitxes i en la construcció de la taula gegant.

Una vegada elaborades, revisades i corregides a classe, les fitxes es van introduir en fundes de plàstic i es van enganxar en una de les parets de la sala polivalent de l'institut. Perquè no quedés una taula massa alta i això dificultés llegir la informació dels elements situats més amunt, es va decidir construir la forma llarga de la taula periòdica. El conjunt fa 2,10 m d'alçada i 6,70 m de llarg. Es poden veure algunes fotografies del procés de construcció de la taula al bloc del departament de ciències de la naturalesa del nostre centre (20).

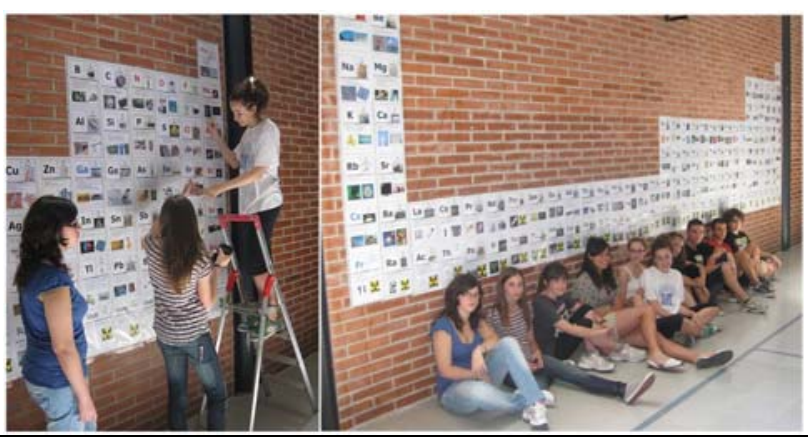

Figura 9. Construcció de la taula periòdica gegant.

La taula va acompanyada d'uns pòsters que contenen informació sobre l'Any Internacional de la Química, l'evolució històrica de la taula periòdica i l'estructura de la taula periòdica moderna.

Al llarg del tercer trimestre del curs l'alumnat de tots els nivells de l'ESO del centre, acompanyats pel seu professor/a de ciències, van realitzar unes breus visites guiades per mirar de prop la taula periòdica gegant i així poder conèixer tots els elements químics i comprovar que molts d'ells tenen aplicacions importants i ben interessants.

A finals de l'any 2011, quan es despengin les fitxes de la paret, es guardaran en una carpeta classificadora. Això ens permetrà disposar d'aquests materials de manera permanent, com a recurs de consulta per a l'alumnat i per si es vol repetir l'experiència un altre curs. 


\section{Referències}

L'última data de consulta de totes les pàgines web és el 29 d'agost de 2011.

(1) Currículum de batxillerat. Decret 142/2008 de 29 de juliol (DOGC núm. 5183)

(2)

http://agora.xtec.cat/iesb7/moodle/course/view.p hp? id=141

(3) http://www.edu365.cat/batxillerat/ciencies/taula/

(4)

http://www.xtec.es/aulanet/ud/ciencies/taula/inici .htm

(5) http://www.taulaperiodica.upc.edu/

(6) http://www.webelements.com/

(7) http://www.chemicool.com/

(8) http://www.ptable.com/

(9) http://www. mcgraw-

hill.es/bcv/tabla_periodica/mc.html
(10) http://periodictable.com/

(11) http://jumk.de/mein-pse/arsen.php

(12) http://www.educaplus.org/play-81-Elementos-

químicos.html

(13) http://www.periodicvideos.com/

(14) http://www.meta-

synthesis.com/webbook/35_pt/pt_database.php

(15) http://www.slideshare.net/joseangelb7/taulaperidica

(16) http://www.educaplus.org/play-88-Símbolos-

de-los-elementos.html

(17)

http://www.sciencegeek.net/Chemistry/taters/Uni t2ElementClasses.htm

(18) http://clic.xtec.cat/db/act_ca.jsp?id=2026

(19)

http://clic.xtec.cat/quaderns/biblioteca/taula_peri odica_ca

(20) http://cienciesb7.blogspot.com/ 